\title{
Tremulation Display in Male Agonistic Behavior of the Black-eyed Leaf Frog (Agalychnis moreletii: Hylidae)
}

\author{
Marcelo Serrano $^{1}$, José Javier Cruz ${ }^{1}$, Melissa Villatoro-Castañeda ${ }^{1}$, and Daniel Ariano-Sánchez ${ }^{1,2 *}$ \\ ${ }^{1}$ Departamento de Biología, Universidad del Valle de Guatemala, Guatemala \\ ${ }^{2}$ Centro de Estudios Ambientales y Biodiversidad CEAB, Universidad del Valle de Guatemala \\ *Corresponding author (Email: dariano@uvg.edu.gt)
}

Citation - Serrano, M., Cruz, J.J., Villatoro-Castañeda, M., \& Ariano-Sánchez, D. (2018). Tremulation display in male agonistic behavior of the black-eyed leaf frog (Agalychnis moreletii: Hylidae). Animal Behavior and Cognition, 5(2), 222-228. https://doi.org/10.26451/abc.05.02.04.2018

\begin{abstract}
The black-eyed leaf frog (Agalychnis moreletii) is a critically endangered hylid frog restricted to humid lowland and lower montane forests of southern Mexico and northern Central America. Very few reports exist on wild reproductive behavior of this species. Lower body tremulation display has been reported as a relevant part of agonistic interactions between males of the related species A. callidryas but has never been reported in other species of Agalychnis. Herein, we present the first report and description of this tremulation display among males of $A$. moreletii in a lower montane forest of Guatemala. Based on our observations, we suggest that this display may serve to prevent physical confrontations among males and might play an important role in defining territories. We also suggest that the difference in fundamental frequency of the tremulations between A. moreletii and A. callidryas may serve to avoid confusing signals between species where they breed sympatrically.
\end{abstract}

Keywords - Agonistic behavior, Vibrational signaling, Tremulation, Agalychnis, Hylidae, Guatemala

The black-eyed leaf frog, Agalychnis moreletii (Duméril, 1853), is a moderate-sized species of hylid frog distinguished from other species of Agalychnis by having uniformly orange flanks and thighs and an extremely dark red eye that appears black to human sight (Duellman, 1970). The species is restricted to small areas of south-central Veracruz, Mexico, western Belize, north-western Honduras, Guatemala, and El Salvador and inhabits humid lowland and lower montane forests occurring in both pristine and disturbed habitat (Campbell, 1998; Köhler, 2011). It is listed under the Critically Endangered category of IUCN red list (Santos-Barrera, Lee, Acevedo, \& Wilson, 2004) and is included under Appendix II of CITES.

Only a few published reports exist documenting breeding behavior of A. moreletii in the wild (Briggs, 2008; Briggs, 2010; Campbell, 1998; Duellman, 1970; Lee, 1996) or in captivity (Burger, 2012). Males descend from the forest canopy and congregate in choruses shortly after sunset and call from vegetation surrounding small lentic bodies of water such as seasonal ponds (Duellman, 1970). Advertisement "zworp" calls function to attract females and aggressive "chuckling" calls are used during intrasexual encounters (Briggs, 2010). The species exhibits pronounced sexual dimorphism in body size, with females much bigger and heavier than males (Figure 1). 
In the related species of red-eyed treefrog (A. callidryas) a lower body vibrational display has been reported as a relevant part of agonistic interactions between males of this species at mating sites during the breeding season (Pyburn, 1970). Later research showed that this kind of vibrational display, also called tremulations, serve an important role in the aggressive interactions of red-eyed tree frogs and suggests that similar vibrational displays may be common among arboreal vertebrates (Caldwell, Johnston, McDaniel, \& Warkentin, 2010). Hill and Wessel (2016) define tremulation as a shaking or trembling behavior that induces vibrations in the substrate, often through the legs, with no percussive impact. This communication via surface-borne vibrations is widely documented in arthropods, such as orthopterans (Cocroft, Shugart, Konrad, \& Tibbs, 2006) and hemipterans (Kavčič, Čokl, Laumann, Blassioli-Moraes \& Borges, 2013), but also had been reported in some vertebrates, such as tree frogs (Caldwell et al., 2010), salamanders (Christensen, Lauridsen, Christensen-Dalsgaard, Pedersen, \& Madsen, 2015) and seals (Bishop, Denton, Pomeroy, \& Twiss, 2015). The analysis of this vibrational signaling in animals, known as biotremology, allows a better understanding of communication through these signals, the propagation process in the environment and how physical variables affect this behavior (Mortimer, 2017). According to Hill (2009) vibrations carried in the substrate are considered to provide a very old and apparently ubiquitous communication channel employed in the contexts of mate location and identification, courtship and mating, maternal care and sibling interactions, predation, predator avoidance, foraging, and general recruitment of family members to work. Herein, we present the first report and description of a tremulation display among males of $A$. moreletii.

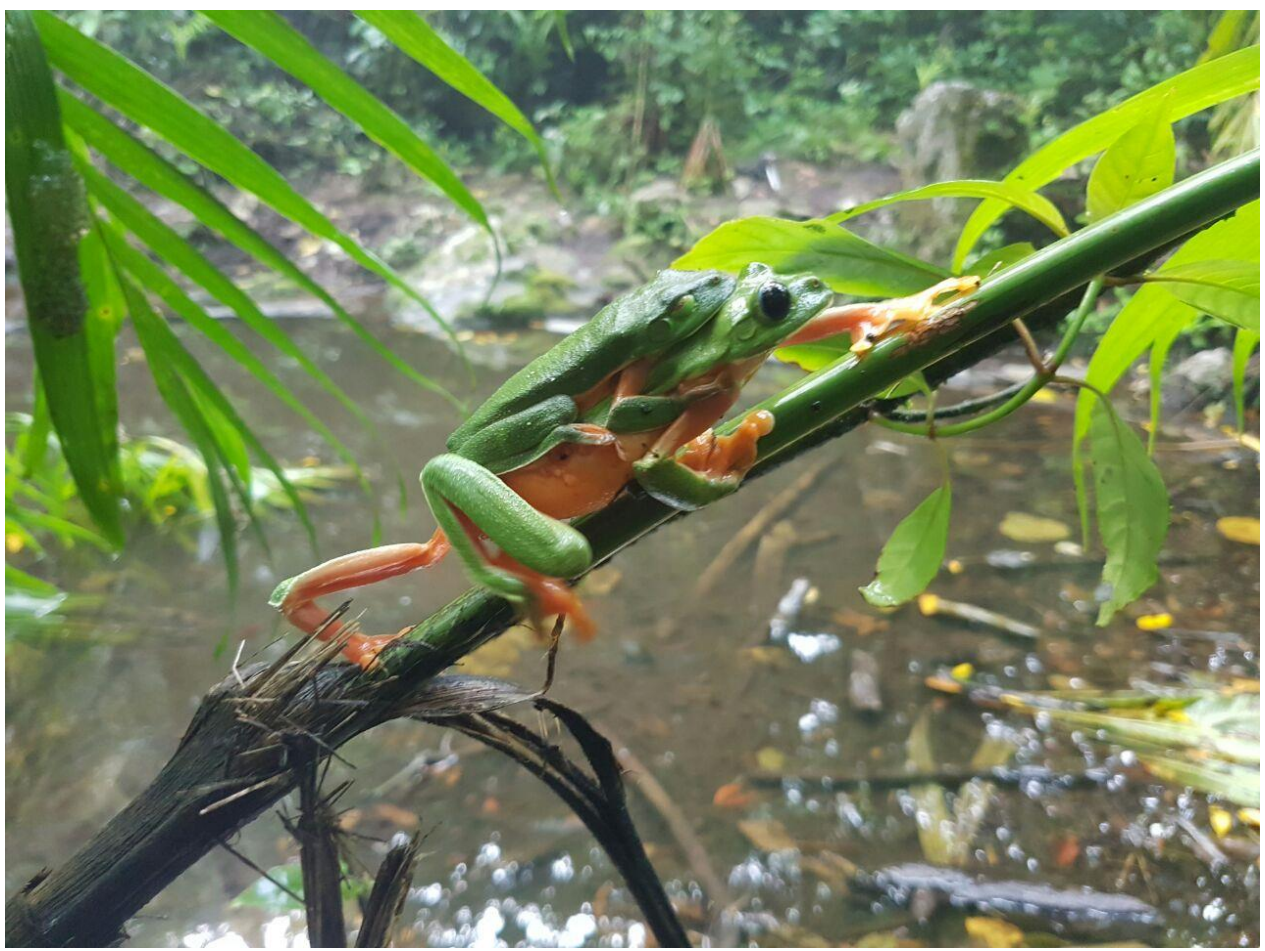

Figure 1. An amplectant pair of Black-eyed Leaf Frogs (Agalychnis moreletii: Hylidae) found in the morning during the breeding season at Reserva Natural Privada Sac Wach Já, Alta Verapaz, Guatemala. The male appears on top of the female and a clutch of eggs is visible at the upper left corner.

\section{Materials and Methods}

The observations were conducted on six different nights throughout the month of May, which marks the end of the dry season (CONAP, 2008). The last visit to the study site on May 20th, 2017 coincided with the first rains of the year's rainy season. 


\section{Description of Study Site}

The study took place in a permanent pond located in a private protected area called Sac Wach Já near San Cristobal Verapaz, in Alta Verapaz, Guatemala (15²5'17.78"N; 90³6'21.02"W; see Figure 2). Some of the most representative species of vegetation in the site are Aguacatillo (Nectandra sp. and Ocotea sp.), various species of Oaks (Quercus spp.), Guarumo (Cecropia obtusifolia), various species of palms (Chamaedorea spp.), Moquillo (Saurauia oreophila), Mountain Rosewood (Dalbergia sp.), Palo de Uva (Parathesis spp.), Mountain Cedar (Trichilia sp. and Cedrela odorata), Bacche (Ageratina ligustrina) and a high abundance of bromeliads, orchids and ferns. The forest that surrounds the protected area is fragmented by pine, cypress, coffee and corn plantations. The dimensions of the pond are $5.5 \mathrm{~m}$ by $8 \mathrm{~m}$ long, with an approximate depth of $1.5 \mathrm{~m}$ at the center. A dense layer of organic material from the surrounding vegetation covers the bottom of the pond. No fish are present and many tadpoles of $A$. moreletii, Lithobates maculatus and possibly other anurans are visible inside the water. The pond is located in a cloud forest at 1,480 $\mathrm{m}$ above sea level and is surrounded mainly by small trees and palms of the species Chamaedorea tepejilote. A. moreletii lay their eggs on top of these palm's leaves, positioned directly above the water level. Because the pond does not dry during the summer, tadpoles, egg clutches and calling males of $A$. moreletii have been observed all year long.

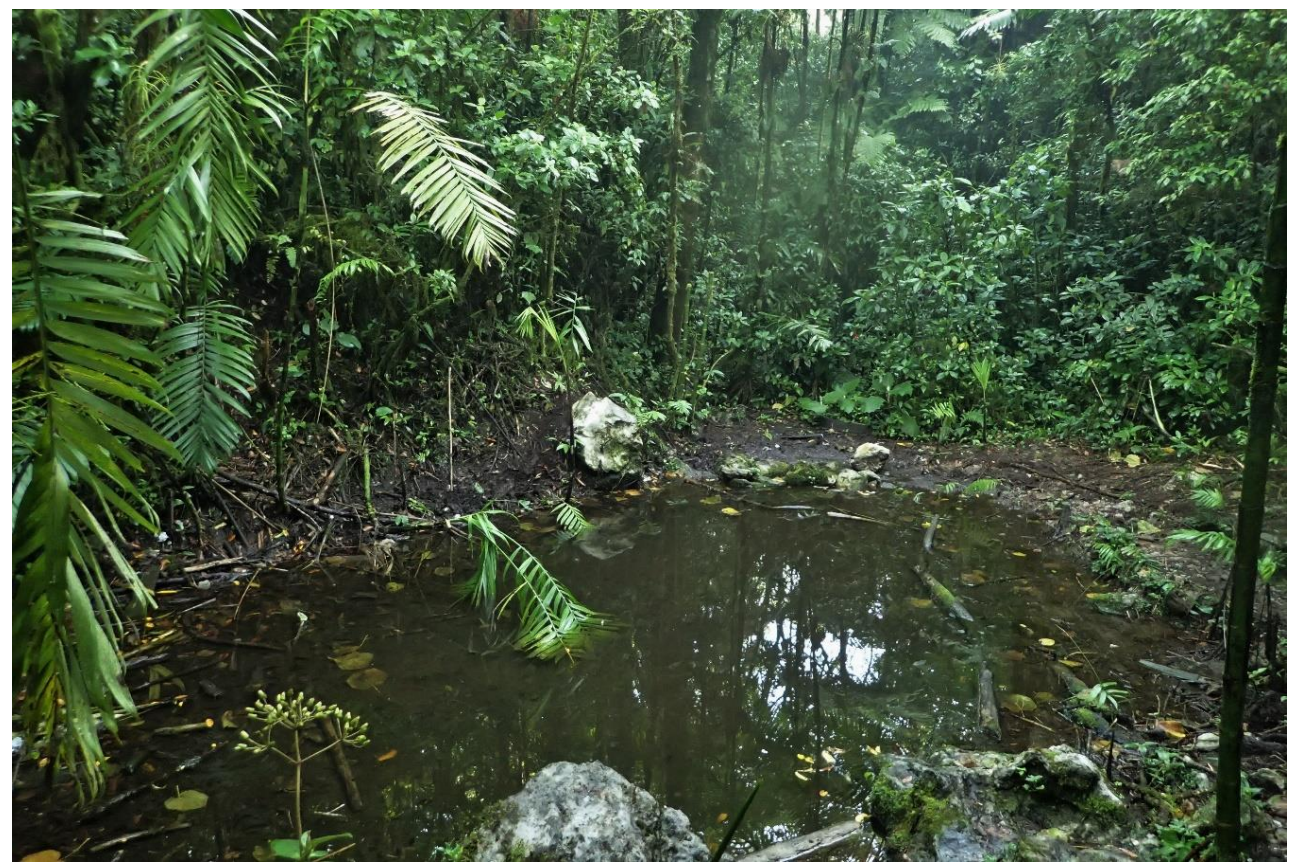

Figure 2. Study site at a seasonal pond in the lower montane forest at Reserva Natural Privada Sac Wach Já, Alta Verapaz, Guatemala.

\section{Behavioral Data Collection}

The observations of agonistic behavior of this species were conducted during the night of May 20th, 2017. Ten male-male event interactions (Figure 3) were recorded using StylusTG-4 Olympus and Sony HXR-NX30E cameras from 7:00 p.m. to 12:00 a.m. These ten recorded events were performed by six different males. Females were identified based on the size difference and males were identified when they produced advertisement or territorial chuckle calls. On this night, the frogs were so abundant that several males were found sharing the same branches. The interactions were recorded using white light as we have seen that this does not affect the expression of the behavior of interest. 


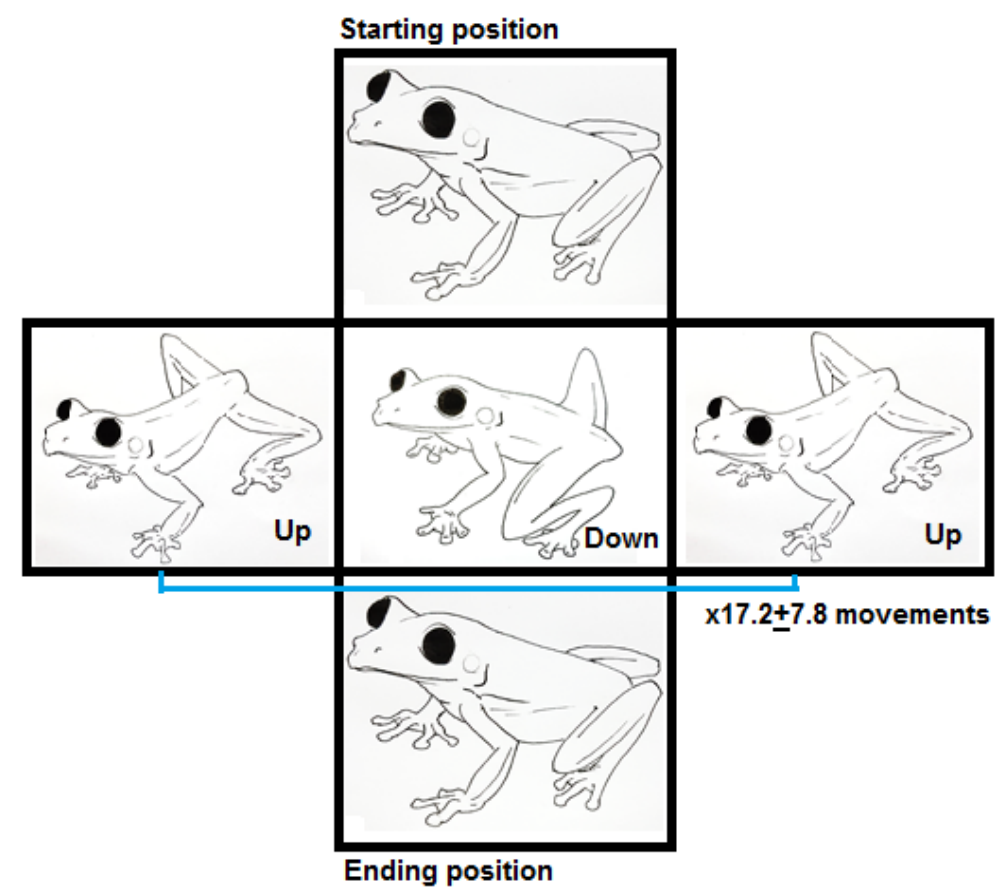

Figure 3. Black-eyed leaf frog (Agalychnis moreletii) generalized ethogram diagram of male tremulation display.

\section{Video Analysis}

The videos were later analyzed using Movie Maker video editor to transform them to slow motion $(0.125 \mathrm{X})$ and we played them back at one-eighth the normal speed to observe them frame by frame and count the number of movements and the duration of each tremulation display. Reliability of movement count was performed by four independent video coders that counted each normal and slow movement display. On two of the videos, disagreements between coders were addressed by using the median of the values as our final result. On the rest, no disagreements where found. A Randolph's free marginal kappa test was performed to calculate the agreement between the values. Frequencies $(\mathrm{Hz})$ were calculated dividing the number of movements by the duration of each display in real time (1.0X). Each movement consisted of the frog lifting his lower back, then lowering it, and concluded when it reached the starting position. Other important information like the male's direction during the display was taken from the videos.

\section{Results}

On the night of May 20th, 2017, we found 40 active individuals of A. moreletii. Only three individuals were identified as females. The sex of the rest of the individuals was not assigned because the observations were made from afar. Most of the frogs were found in plants surrounding the pond at knee height, others were seen above ground in palms at approximately two meters high. Males were spotted in individual branches and leaves. Advertisement calls and territorial chuckle calls were heard upon arrival and males were active. Their activity was uninterrupted when we approached to record the behaviour. On ten occasions, agonistic interactions between males were observed. This interaction was observed when two or three males shared the same branch. Visual contact between males was observed in only one of these ten recorded events.

These agonistic interactions between males consisted of males approaching one another in an aggressive manner to remove the other male from its calling site. The first observation of tremulation display was recorded at 7:46 pm, when one male appeared to be following the other male's path, jumping on the same spots and climbing on the same direction. We recorded a total of six different males 
performing the tremulation display (Figure 3). The average frequency of the tremulation display was 7.3 $\pm 0.9 \mathrm{~Hz}$. Each encounter lasted an average of $2.4 \pm 1.1 \mathrm{~s}$ with $17.2 \pm 7.8$ up and down tremulation movements per act (Table 1), with a free marginal kappa value of 0.75 for the measurement of agreement. A rule of thumb is that a kappa of .70 or above indicates adequate interrater agreement.

Table 1

Metrics of Tremulation Display in Six Male Black-eyed Leaf Frogs A. moreletii

\begin{tabular}{ccccc}
\hline Video code & Male ID & Frequency $(\mathrm{Hz})$ & Duration $(\mathrm{s})$ & No. of movements \\
\hline 1.1 & 1 & 6.71 & 1.64 & 11 \\
1.2 & & 8.05 & 0.87 & 7 \\
2.1 & 2 & 7.17 & 2.65 & 19 \\
3.1 & 3 & 8.70 & 1.61 & 14 \\
3.2 & & 7.46 & 2.28 & 17 \\
4.1 & 4 & 8.24 & 1.82 & 15 \\
5.1 & & 7.03 & 4.41 & 31 \\
5.2 & 5 & 5.66 & 1.59 & 9 \\
5.3 & & 6.05 & 3.47 & 21 \\
6.1 & 6 & 7.61 & 3.68 & 28 \\
\hline Mean & & $7.3 \pm 0.9$ & $2.4 \pm 1.1$ & $17.2 \pm 7.8$ \\
\hline
\end{tabular}

Each act consisted of the male extending both hind limbs, uplifting his hind end followed by elevating and lowering his hind end repeatedly (Figure 4). Some encounters were followed by aggressive interactions of one male grappling another (links to example videos appear here and here). We also observed males kicking other males, some of which ended up falling off the leaves. Several tremulation displays were observed accompanied by kicks, pushes and low "chuckle" calls between males. One amplectant male was observed doing a tremulation display while being on top of a female. The displays were performed regardless of the light condition, under white light or infrared capable cameras.

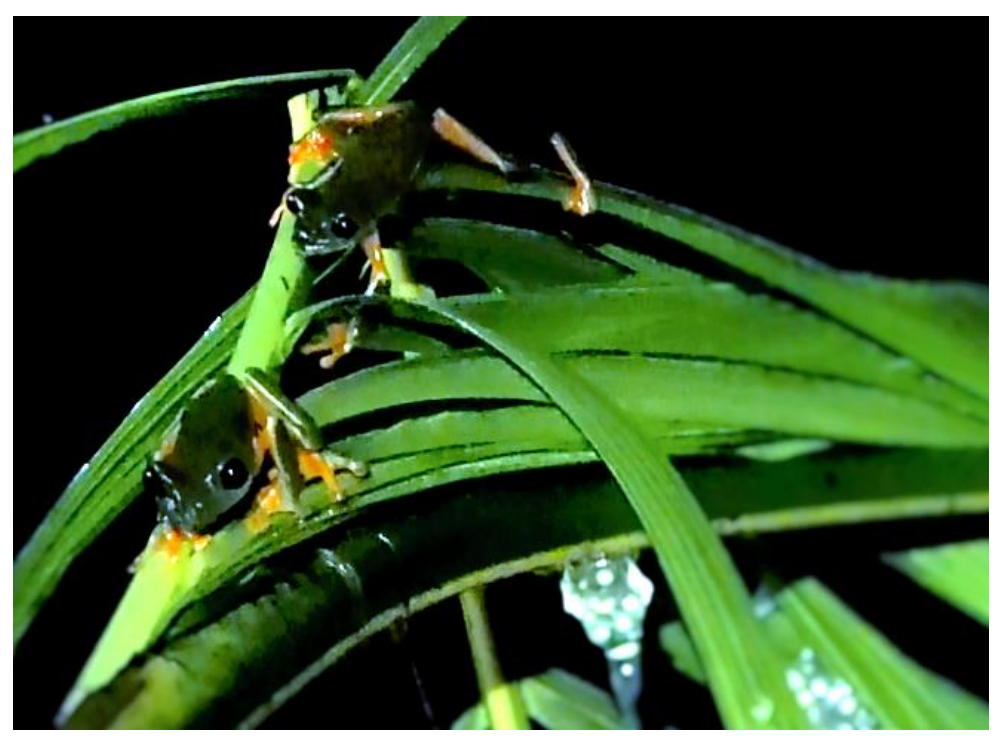

Figure 4. A male black-eyed leaf frog (Agalychnis moreletii) performing a tremulation display to another male. In the background, two egg clutches can be observed on top of the palm leaves. 


\section{Discussion}

Tremulation displays are present and play an important role in the agonistic behavior of $A$. moreletii and may have many purposes in the communication between individuals. Because we observed that only one of the ten events recorded had visual contact between males, we consider that substrateborne vibrational signals transmitted via plant stems and leaf stalks are the most important form of communication of this tremulation display. Vibrations in the substrate may carry important information about the males (Caldwell et al., 2010) as it is known that tremulations tend to produce low-frequency vibration signals in a narrow range that vary with the morphology of the sender, as well as with the body motions that create the signals (Hill, 2009). Intensity and duration of the tremulations may serve as an honest signal of the male's physical health and vitality. In most of the aggressive interactions observed, tremulations were produced before wrestling. According to Martins, Pombal, and Haddad (1998) a male frog should fight only in extreme situations, and anurans make use of other activities to avoid the risks and costs of physical combats, such as being seriously wounded or preyed upon. Based on our observations, we suggest that the displays of $A$. moreletii may serve to prevent physical confrontations.

Consistent with the observations of A. callidryas (Pyburn, 1970), males of A. moreletii use both territorial chuckle calls as well as tremulations both with and without the direct presence of females. However, the frequency and intensity of these behaviors were increased when a female was near. This suggests that the behavior observed in A. moreletii might play an important role in defining territories or calling locations, as it has been reported that the tremulation in A. callidryas can play part in an aggressive encounter between adult males following aggressive calling and posturing in high density situations (Gonzalez \& Briggs, 2011).

These events were observed during the beginning of the rainy season, whereas no activity was recorded during previous observations at the same study site in the dry season. Thus, we infer that this type of behavior increases or might even be exclusive of this season.

The presence of tremulation in A. moreletii might have the same function as the use of substrate vibration as a form of communication that had been previously reported by Caldwell, and colleagues (2010) for A. callidryas. The frequency we observed in A. moreletii $(7.3 \pm 0.9 \mathrm{~Hz})$ is lower than the frequency reported by Caldwell et al. (2010) for A. callidryas $(12.1 \pm 1.9 \mathrm{~Hz})$. As there are some areas where both species breed sympatrically (Briggs, 2008), this difference in the fundamental frequency of the tremulations may serve to avoid confusing signals between species sharing the same breeding habitat. This is especially important as it has been reported that species communicating via tremulations transmitted through plant stems and branches face important limitations on this vibrational communication system for simultaneously detecting several conspecific and/or heterospecific signals, and discriminating between them (De Groot, Čokl, \& Virant-Doberlet, 2011). This is the first report of tremulation display among males in A. moreletii.

\section{Acknowledgments}

We thank Ruth Prem and José Serrano, owners of Reserva Natural Privada Sac Wach Já, for their support with the logistics and permits for visiting the field site. We thank Felipe Lem for his guidance and company in the field. We thank Luz de Jesús Recinos for her help with the field work. Thanks to the Biology Department of Universidad del Valle de Guatemala for providing the equipment for the field work. Thanks to María Renée Álvarez for helping us identify the pond's surrounding vegetation. Thanks to two anonymous reviewers whose comments improved many parts of the paper. 


\section{References}

Bishop, A. M., Denton, P., Pomeroy, P., \& Twiss, S. (2015). Good vibrations by the beach boys: Magnitude of substrate vibrations is a reliable indicator of male grey seal size. Animal Behaviour, 100, 74-82.

Briggs, V. S. (2008). Mating patterns of red-eyed treefrogs, Agalychnis callidryas and A. moreletii. Ethology, 114, 489-498.

Briggs, V. S. (2010). Call trait variation in Morelett's tree frog, Agalychnis moreletii, of Belize. Herpetologica, 66, 241-249.

Burger, R. M. (2012). A brief note on reproduction in Morelet's leaf frog, Agalychnis moreletii (Duméril). Bulletin of the Chicago Herpetological Society, 47, 26.

Caldwell, M. S., Johnston, G. R., McDaniel, J. G., \& Warkentin, K. M. (2010). Vibrational signaling in the agonistic interactions of red-eyed treefrogs. Current Biology, 20, 1012-1017.

Campbell, J. A. (1998). Amphibians and reptiles of northern Guatemala, the Yucatán, and Belize. OK: University of Oklahoma Press.

Christensen, C, B., Lauridsen, H., Christensen-Dalsgaard, J., Pedersen, M., \& Madsen, P. T. (2015). Better than fish on land? Hearing across metamorphosis in salamanders. Proceedings of the Royal Society B, 282, 20141943.

Cocroft, R. B., Shugart, H. J., Konrad, K. T., \& Tibbs, K. (2006). Variation in plant substrates and its consequences for insect vibrational communication. Ethology, 112, 779-789

CONAP. (2008). Guatemala y su biodiversidad: Un enfoque histórico, cultural, biológico y económico. Guatemala City, Guatemala: Serviprensa S.A.

De Groot, M., Čokl, A., \& Virant-Doberlet, M. (2011). Species identity cues: Possibilities for errors during vibrational communication on plant stems. Behavioral Ecology, 22, 1209-1217.

Duellman, W. E. (1970). The hylid frogs of Middle America. Monographs of the Museum of Natural History, University of Kansas, 1, 1-753.

Gonzalez, S. C., \& Briggs, V. S. (2011). Aggression in froglets of red-eyed treefrogs, Agalychnis callidryas. Herpetology Notes, 4, 315-318.

Hill, P. S. (2009). How do animals use substrate-borne vibrations as an information source? Naturwissenschaften, 96, 1355-1371.

Hill, P. S., \& Wessel, A. (2016). Biotremology. Current Biology, 26, 181-187.

Kavčič, A., Čokl, A., Laumann, R. A., Blassioli-Moraes, M. C., \& Borges, M. (2013). Tremulatory and abdomen vibration signals enable communication through air in the stink bug Euschistus heros. PLoS ONE, 8, e56503.

Köhler, G. (2011). Amphibians of Central America. Offenbach, Germany: Herpeton Verlag Press.

Lee, J. C. (1996). The amphibian and reptiles of the Yucatán peninsula. New York: Cornell University Press.

Martins, M., Pombal, J. P., \& Haddad, C. (1998). Escalated aggressive behavior and facultative parental care in the nest building gladiator frog, Hyla faber. Amphibia-Reptilia, 19, 65-73.

Mortimer, B. (2017). Biotremology: Do physical constraints limit the propagation of vibrational information? Animal Behaviour, 130, 165-174.

Pyburn, W. (1970). Breeding behavior of the leaf-frogs Phyllomedusa callidryas and Phyllomedusa dacnicolor in Mexico. Copeia, 2, 209-218.

Santos-Barrera, G., Lee, J., Acevedo, M., \& Wilson, L. D. (2004). Agalychnis moreletii. The IUCN red list of threatened species. 